\title{
Quando falar vira ordem: a construção FALAR PARA V. infinitivo em Português, uma explicação cognitiva*
}

\author{
Vanda Maria Cardozo de Menezes ${ }^{a}$
}

\begin{abstract}
Resumo
Neste artigo, focalizamos a construção FALAR PARA $V$.infinitivo no Português do Brasil (PB), na oralidade e na escrita, em contextos em que emerge sentido manipulativo. O compartilhamento de dominios semântico-gramaticais entre os verbos pedir e falar, tais como a conceptualização de "atividade comunicativa com o uso da palavra" e a possibilidade de complementação com que $V$. finito e com para V.infinitivo, direcionou-nos para a investigação sobre as similaridades e diferenças que as construções com esses verbosapresentam.Com tal propósito, estabelecemos contraste com o Português Europeu (PE), na mesma sincronia, considerando o pressuposto cognitivista de que diversificações semânticas são resultantes de diferenças de conceptualização. Buscamos, assim, identificar as operações cognitivas envolvidas nos processos de conceptualização que permeiam as escolhas dos falantes, tanto no sentido para a estabilidade quanto para a mudança semântica. As concepções de perspectivação e de subjetificação, tomadas dos estudos desenvolvidos por Traugott (1989), Traugott e Dasher (2002) e Langacker (2008), nortearam a análise dos dados, que aponta a construção FALAR PARA V.infinitivo como um exemplo de processo de mudança semântica no Português do Brasil (PB), na oralidade e na escrita.
\end{abstract}

Este artigo é resultante de pesquisa realizada em estágio de Pós-doutorado na Universidade Católica de Braga, Portugal, sob a supervisão do Prof. Doutor Augusto Soares da Silva, no período de março a agosto de 2017.
Palavras-chave: Construção FALAR PARA V. infinitivo. Subjetificação. Linguística Cognitiva
Recebido em: 12/06/2018 Aceito em: 14/08/2018

a Programa de Pós-graduação em Estudos de Linguagem da Universidade Federal Fluminense (UFF).

E-mail: vcmenezes@terra.com.br. 


\section{Introdução}

Ao investigar as motivações pragmáticas e cognitivas que pudessem explicar alguns casos de complementação com para infinitivo em português, deparamo-nos com uma significativa frequência dessa construção com o verbo falar, em contextos em que se constrói uma conceptualização de manipulação, agregada ao valor enunciativo desse verbo. O entendimento de que "exigências de alinhamento de formas em novas funções sintáticas refletem adaptações conceptuais das estruturas para finalidades específicas" (LANGACKER, 2008, p.432) guiou a investigação, deixando-nos também atentos aos fenômenos de regularidade da mudança semântica.

As noções de perspectivação e subjetificação (TRAUGOTT, 1989; TRAUGOTT e DASHER, 2005) nos permitiram formular algumas indagações que julgamos relevantes para este estudo e para a continuidade da pesquisa: a) Em que medida essas construções de complementação constituídas por para infinitivo se relacionam semanticamente com aquelas construções de finalidade com estrutura semelhante, ou seja, também com para infinitivo; b) Que motivações cognitivas e pragmáticas explicariam o uso de para infinitivo com verbos de atividade comunicativa, em contextos em que o falante deseja expressar maior apropriação da palavra por parte do sujeito do verbo da matriz, configurando uma conceptualização de manipulação; c) Em que sentido a pesquisa diacrônica da trajetória das construções com os dois verbos - pedir e falar - pode contribuir para explicar, do ponto de vista cognitivo, o surgimento e o progressivo uso desses verbos com para infinitivo, na oralidade e na escrita em PB. Neste artigo, trataremos mais das duas primeiras questões enunciadas, mas já daremos encaminhamento à última.

Para a análise das construções PEDIR/FALAR PARA V.infinitivo na oralidade, valemo-nos do corpus Museu da Pessoa (MP), um corpus falado transcrito disponibilizado pela Linguateca (COSTA, 2008) nas duas variantes que esse corpus contempla: Português do Brasil (PB) e Português Europeu (PE). Para a verificação do uso das construções PARA V. infinitivo na escrita, recorremos ao corpus CONDIV-Port, também disponibilizado pela Linguateca, composto por textos 
de jornais de esportes e revistas de moda e saúde, nas duas comunidades linguísticas, Brasil e Portugal.

\section{Outros estudos sobre a construção PARA V.infinitivo}

No exame das construções infinitivas iniciadas por para em estudo anterior (MENEZES, 2001), com base em amostras de oralidade e de escrita, deparamo-nos com muitas construções que se diferenciavam das adverbiais prototípicas de finalidade. Há construções que se referem ao conteúdo de uma proposição ou de uma predicação (adverbiais circunstanciais); construções que se referem a termos nominais (adnominais), e construções que se ligam a predicados, representados em geral pelas categorias nome (completivas nominais), adjetivo (completivas adjetivais) e verbo (objetivas diretas e indiretas ou completivas verbais). Há, ainda, as construções que ocupam a posição de predicativo (as predicativas) e as construções com verbo dar.

Em dois outros trabalhos (MENEZES, 2004, 2017), foi estudada a construção TERSN PARA V. infinitivo, concluindose que o verbo ter, nas diferentes perspectivações relacionadas com o valor de posse, seleciona um sujeito não controlador, o que desfavorece a construção do contexto típico das estruturas adverbiais que expressam finalidade.

Em estudo sobre infinitivos com sujeito explícito em português e espanhol, Vanderschueren (2013, p. 95), após caracterizar as finais prototípicas com para como orações que expressam geralmente o objetivo do sujeito da principal (ou oração matriz, como chamamos), observa que "quando falta algum traço básico da semântica final, por exemplo a volição ou a animacidade, o objetivo do sujeito não se apresenta como final pura, mas como utilidade ou como consequência".

Torrent (2009), ao estudar a rede de construções PARA (SN) V. infinitivo, apresenta 17 padrões construcionais, entre os quais o referido esquema pode funcionar como um dos argumentos perfilados por outra construção; ou, ainda, como uma construção de perspectivização discursiva.

Diferenças de perspectivação relacionadas com o papel semântico do sujeito foram também observadas por Silva (2012, p.18), ao considerar o processo de gramaticalização das construções de complemento infinitivo com verbos 
causativos e perceptivos. Segundo o autor, nas construções estruturalmente mais integradas, o sujeito da oração infinitiva vai gradualmente perdendo o controle sobre a sua própria atividade, deixa de ser o foco específico de atenção dentro do evento subordinado e, em consequência disso, a relação causal ou a relação perceptiva entre evento principal e evento subordinado passa a ser mais direta.

Silva (2008), ao analisar construções como "A Maria fez o Zé sair do restaurante" e "A Maria fez com que o Zé saísse do restaurante", afirma que a variação entre complementação infinitiva e complementação finita, apresentada em cada exemplo pelo contraste entre a primeira e a segunda construção, não se assenta apenas em uma diversidade formal, antes disso, essa variação "reflete um contraste conceptual que se deixa explicar adequadamente em termos de operação de perspectiva" (SILVA, 2008, p.21). A construção completiva infinitiva com verbos causativos exprime uma causação direta, enquanto a construção completiva finita exprime uma causação indireta e inferida.

Esse esquema cognitivo da causação também foi adotado por Torrent (2009), para explicar a complementação de verbos proposicionais e de movimento com o uso de para infinitivo, tais como pedir, levar e contratar. Segundo o autor,

o esquema cognitivo da causação emerge quando da integração do evento causador - manipulação, proposição ou movimento - ao evento resultante, codificado pelo esquema para (SN) infinitivo. (TORRENT, 2009, p. 89)

Assim, considerando os estudos aqui apresentados, podemos confirmar que, direta ou indiretamente, a perspectiva cognitiva se faz presente, especialmente na concepção de gramática como inventário estruturado por relações de categorização de esquema-instância e de protótipo-extensão, relações de inclusão, integração e outras. E todas as unidades linguísticas, como sintetizam Silva e Bartoréo (2010, p. 231), "simbolizam conceptualizações, constituindo-se como rotinas cognitivas convencionalizadas ou estabelecidas pelo uso dentro de uma comunidade linguística". 


\section{Conceptualização, perspectivação e subjetificação}

Um consenso entre os teóricos cognitivistas é a constatação de que há modos alternativos de conceptualizar determinada situação. $\mathrm{O}$ destaque concedido à categoria perspectiva, dentre as demais categorias identificadas nas operações de conceptualização, pode ser justificado, antes de tudo, pela concepção de gramática que se adota, observam Silva e Bartoréo (2010, p. 230). O entendimento da gramática como "sistema de estruturação conceptual" implica a concepção de perspectivação conceptual para explicar a complexidade desse sistema, que envolve capacidades cognitivas gerais, como percepção, atenção, categorização e memória, conhecimentos de mundo ou enciclopédicos e mecanismos imaginativos, como metáfora, metonímia, mesclagem conceptual, evocação de entidades fictivas.

As operações de conceptualização, afirma Silva (2008, p. 20), efetivamente, envolvem "uma capacidade $\operatorname{cogn}($ osc)itiva geral e uma capacidade que mostra que falar implica sempre uma escolha". Essas escolhas é que nos permitem entrever, no processo de conceptualização, operações específicas de perspectivação conceptual (cf. construal, em inglês).

Em um exame criterioso de diferentes propostas de classificação das operações de perspectivação conceptual desenvolvidas no âmbito da Linguística Cognitiva, Silva (2009, p. 39) conclui que, embora as operações de perspectivação conceptuais se mostrem centrais na cognição e na linguagem, "parece não ser possível organizá-las num sistema de classificação exaustiva". Cabe, antes de mais nada, reconhecer que essas operações se combinam entre si de tal modo que determinada construção linguística, geralmente, resulta da combinação de diferentes operações, residindo aí a razão de ela ser única e distinta de outras construções.

Verhagen (2007, p. 48-49), ao reiterar o princípio fundamental da Linguística Cognitiva, o de que a semântica é primariamente cognitiva, nos direciona também para as noções de perspectiva e de subjetividade. Essas noções têm em comum o fato de capturar aspectos específicos da conceptualização, que não são suficientemente analisados em termos de propriedades do objeto, mas que envolvem necessariamente um sujeito da conceptualização. Cada construção impõe 
um perfil na interpretação de uma dada conceptualização e tal perfil está relacionado com a perspectiva, a atenção e a intencionalidade, consideradas como subtipos de operação de perspectivação conceptual.

Entre os mecanismos cognitivos mencionados, citaremos em nosso estudo o da mesclagem conceptual, apresentado com maior vigor na obra de Fauconnier e Turner (2002, p. 353), com base no fundamento de que o pensamento humano é estruturado em unidades cognitivas - domínios ou espaços mentais - e que os humanos podem reunir ideias e referências de todo o tipo de diferentes maneiras, embora as mesclagens que se efetivam no discurso ocorram de maneira bem mais restrita, isso porque se trata de recursos linguísticos localmente situados, ou seja, são unidades dependentes da situação de interação.

Esse viés discursivo da Linguística Cognitiva é também encontrado nos conceitos de subjetificação e intersubjetificação, que vêm ocupando lugar central nas abordagens cognitivistas e funcionalistas da mudança semântica e da gramaticalização, nos últimos anos. Soares esclarece acerca desses conceitos:

constituem processos de perspectivação conceptual e mudança de significado no sentido de um maior envolvimento do conceptualizador/locutor, pela intromissão da sua perspectiva ou atitude (subjetificação), ou no sentido de maior saliência da relação entre locutor e interlocutor (intersubjetificação). (SOARES, 2011, p. 93)

Entendemos a acuidade da distinção entre subjetificação e intersubjetificação (TRAUGOTT; DASHER, 2002), mas, aqui, na análise da construção FALAR PARA V. infinitivo, trataremos subjetificação como uma operação que envolve necessariamente intersubjetificação, considerando que o sujeito se caracteriza como social e coletivo, como temos ressaltado nos estudos que vimos realizando sobre referenciação (MENEZES, 2015), com base em proposta de Mondada e Dubois (2003).

Não podemos deixar, porém, de trazer a leitura de Soares (2011, p. 94) acerca das posições de Traugott (1989) e Langacker (1999) sobre subjetificação: "as diferenças entre as duas abordagens resultam sobretudo da perspectiva teórica sobre a linguagem assumida por cada autor, pelo que elas são, no essencial, compatíveis e até complementares". Antes dessa conclusão, Soares esclarece: 
Traugott focaliza o processo diacrônico e a dimensão pragmática da subjetificação, entendendo este fenômeno como um processo de mudança pelo qual significados que descrevem uma situação externa passam a indicar perspetivas, atitudes e crenças do locutor em relação a essa situação. Langacker focaliza o próprio processo de conceptualização envolvido e entende a subjetificação em termos de perspetivação e como um processo de atenuação da conceção objetiva de uma entidade ou situação. Curiosamente, Traugott vê o fenômeno em termos de reforço pragmático, ao passo que Langacker prefere falar em atenuação semântica. (SOARES, 2011, p. 94)

Seguindo a interpretação dada por Soares (2011), que acabamos de citar, tomaremos aqui as contribuições das duas abordagens, concordando plenamente com a avaliação de que são complementares.

Segundo Traugott (1989, p. 34-35), a subjetificação resulta da combinação de três tendências específicas de mudança semântica, a saber:

- tendência I: de significados que descrevem uma situação externa para significados que descrevem uma situação interna (avaliativa/percetiva/ cognitiva);

- tendência II: de significados baseados na situação externa ou interna para significados baseados na situação textual ou metalinguística;

- tendência III: maior propensão para significados baseados na atitude/ estado de crença do falante perante o descrito na proposição.

Segundo Langacker (1999, p.155-56), a subjetificação ou atenuação semântica é um fenômeno gradual e multifacetado que se caracteriza em relação a quatro parâmetros de mudança:

- mudança de estatuto: de atual para potencial ou de específico para genérico;

- mudança de foco de atenção: de perfilado para não perfilado;

- mudançade domínio: da interação física para a interação experiencial ou social;

- mudança de fonte de atividade: de entidade "em cena" para entidade "fora de cena". 
Langacker assinala que a subjetificação dá lugar a formas gramaticalizadas ao longo de um período de tempo e, no processo gradual de gramaticalização, certos sentidos ou funções podem coexistir, dispostos em camadas, numa mesma forma.

Por último, antes de passarmos ao exame das construções V. PEDIR/FALAR PARAinfinitivo, queremos observar que subjetificação não exclui convencionalidade/ estabilização, o que plenamente justifica a posição de considerar subjetificação e intersubjetificação em conjunto.

\section{Construções PEDIR/FALARPARAinfinitivo}

A seguir, dois exemplos de construções no português brasileiro, um para cada tipo de verbo - pedir e falar - servirão para dar uma noção do que vamos tratar; ou seja, daquelas construções em que para infinitivo se junta ao verbo pedir e falar de tal modo que, sintaticamente, quase se equivale à complementação com que + verbo forma finita $\left(1^{\prime}\right)$ e $\left(2^{\prime}\right)$. Lembremos antes que, por princípio cognitivista, cada um dos tipos de construção impõe um perfil, de modo que a interpretação já deverá não ser a mesma.

(1) Mas, o jornalista que me entrevistou, que eu pedi pra não colocar essa parte, ele colocou. (MP, E118BR-378)

(1') Mas, o jornalista que me entrevistou, que eu pedi pra que não colocasse essa parte, ele colocou.

(2) E largava tudo uma bagunça, então a gente começou com o trabalho lá de conversar com as pessoas, de dar saquinho, de falar para levarem o seu lixo, porque aquele lugar é uma APA... (MP, E132"-BR-410)

(2') E largava tudo uma bagunça, então a gente começou com o trabalho lá de conversar com as pessoas, de dar saquinho, de falar para que levassem o seu lixo, porque aquele lugar é uma APA...

Aplicando a análise de Silva (2008) para os causativos, diremos que a construção completiva infinitiva com o verbo pedir, exemplo (1), exprime manipulação direta, enquanto a 
completiva finita, exemplo $\left(1^{\prime}\right)$, exprime manipulação indireta e inferida. Estamos aqui considerando o verbo pedir como manipulativo, na medida em que o sujeito atua sobre o locutor e requer dele uma ação. Observe-se que, nesse exemplo, o sujeito de pedir é agente e manipulador, embora não tenha obtido sucesso, pois o jornalista, objeto e alvo da ação, não lhe teria "obedecido".

Com o verbo falar, poderíamos interpretar que, ao usar esse verbo com um complemento que exprime finalidade/ intencionalidade, como o faz o complemento para infinitivo, o domínio cognitivo da causação também emerge. Consideramos que a mesma relação semântica se aplica ao verbo falar, embora se aplique mais adequadamente ao verbo pedir, e não tanto ao verbo falar, dadas as características semânticas de cada um desses itens lexicais.

Essa observação sobre a natureza semântica do item lexical requer de nós uma justificativa. Embora tenhamos seguido, desde o primeiro estudo sobre construções PARA V. infinitivo (MENEZES, 2001), um conceito de construção que reúne léxico e gramática como continuum, tal como formula Langacker (2008, p. 16), temos que reconhecer, com Traugott e Dasher (2002, p.3), o papel do item lexical no desencadeamento da mudança construcional, "dada a natureza do léxico, que está longe de permanecer imune à referência e, portanto, às mudanças de estilos de vida e ideologias". Mesmo que o léxico não seja tomado separadamente no exame das construções, não se ignora o seu papel estabilizador (MONDADA e DUBOIS, 2003, p. 41).

A questão da referência é também considerada por Langacker (2008), ainda que não diretamente apontada. O autor afirma:

No discurso conceptualizamos não apenas o que estamos dizendo sobre algo, mas também o contexto em todas as suas dimensões, incluindo nossa avaliação do saber e das intenções de nosso interlocutor. Em vez de ser tomada como isolada, conceptualização, portanto, deveria ser tomada em sua função primária de se perceber o mundo" (LANGACKER, 2008, p. 29).

Langacker (2008, p. 51) também reafirma seu posicionamento de não estabelecer uma fronteira rígida entre semântica e pragmática, apesar de a distinção ser útil. Não é 
por acaso que o autor considera a importância do fenômeno de subjetificação e o designa como uma das operações de perspectivação. As diferenças apontadas nos exemplos dados (1) e (2), com os verbos pedir e falar em complementação de construções finitas e infinitas, demonstram a importância dos aspectos pragmáticos no estudo cognitivo das construções gramaticais. Observem-se esses dois exemplos a seguir, interpretados como apresentando uma atenuação do pedido, por conta da construção PARA QUE V. subjuntivo.

(3) Fulano de tal morreu, a família pede para que não sejam enviadas flores nem coroa no enterro. (MP, E138-BR-106)

(4) Com a vitória garantida, Zizinho pediu para que ninguém ficasse se arriscando muito. (CONDIV, BR-JSports-70-46317)

Mas, apesar dessas observações sobre o papel da intencionalidade na escolha de uma ou outra construção e, consequentemente no processo de mudança semântica, há também de se observar aqui a situação de estabilidade/ convencionalidade gerada pelo compartilhamento sociocognitivo no uso da língua.

No exame das 194 construções com o verbo pedir, sendo 97 ocorrências na oralidade, corpus MP, e 97 ocorrências na escrita, corpus CONDIV-Port, observa-se que o uso desse verbo é preponderante com a preposição para no PB (122/161 ocorrências). Em PE, apesar de poucas ocorrências, registrase maior frequência de uso da construção com infinitivo na oralidade (13/14 ocorrências), fenômeno que deverá ser acompanhado com observação em outros corpora.

Tabela 1 - PEDIR PARA QUE V. finito e PEDIR PARA V. infinitivo

\begin{tabular}{cccccc}
\hline & \multicolumn{2}{c}{ Português Europeu (PE) } & \multicolumn{2}{c}{ Português do Brasil (PB) } & TOTAL \\
\hline \multirow{5}{*}{ Oral } & $\begin{array}{c}\text { Pedir (para) que } \\
\text { V. finito }\end{array}$ & $\begin{array}{c}\text { Pedir para } \\
\text { V. infinitivo }\end{array}$ & $\begin{array}{c}\text { Pedir (para) que } \\
\text { V. finito }\end{array}$ & $\begin{array}{c}\text { Pedir para } \\
\text { V. infinitivo }\end{array}$ & \\
& $01 / 14$ & $13 / 14$ & $07 / 83$ & $78 / 83$ & 97 \\
\multirow{2}{*}{ Escrita } & $(7 \%)$ & $(93 \%)$ & $(9 \%)$ & $(91 \%)$ & $(50 \%)$ \\
& $10 / 19$ & $07 / 19$ & $33 / 78$ & $45 / 78$ & 97 \\
\multirow{2}{*}{ TOTAL } & $(53 \%)$ & $(47 \%)$ & $(40 \%)$ & $(60 \%)$ & $(50 \%)$ \\
\hline & $(33 \%)$ & $20 / 33$ & $40 / 161$ & $122 / 161$ & 194 \\
& $(67 \%)$ & $(25 \%)$ & $(75 \%)$ & $100 \%$ \\
\hline
\end{tabular}


Segue mais um exemplo da construção PEDIR QUE no corpus Museu da Pessoa em PB, para enfatizar que o valor manipulativo se mantém nessa construção também, dentre outras motivações, por conta da semântica do verbo pedir.

(5) Foi aí que ele começou a chorar, disse-me que não tinha dinheiro nenhum e pediu que não o deixasse sozinho. (MP, E039-PT-150)

Essa conceptualização generalizadamente de manipulação que se constrói com o verbo pedir não se dá, entretanto, de igual modo com o verbo falar. Aqui, com esse verbo, o processo requer muito mais a complementação para infinitivo e, por vezes ainda, mais apoio do contexto, como se pode verificar no exemplo (2), já apresentado, em que o enunciador especifica todo um trabalho de convencimento: "então a gente começou com o trabalho lá de conversar com as pessoas, de dar saquinho, de falar para levarem o seu lixo, porque aquele lugar é uma APA..."

Assim, diferentemente de PEDIR QUE, a construção FALAR QUE não conceptualiza manipulação, pelo menos não o faz nos contextos que analisamos. A construção FALAR QUE V. finito mantém sempre a conceptualização enunciativa/ proposicional na oralidade e na escrita, em PE e PB, como nos exemplos seguintes, extraídos do corpus de oralidade em PB e apresentados justamente por considerarmos que o contexto favoreceria um tom mais incisivo/manipulativo.

(6) Ela falou que era só para complementar a merenda das crianças, eu falei: ... (MP, E132-BR-290)

(7) Olha, professora, falei para a minha mãe que a gente combinou que não pode jogar lixo na rua, mas a minha mãe está jogando. (MP, E132"-BR-340)

Considerando o verbo falar, os dados apontam que a conceptualização manipulativa emerge na construção para infinitivo no português brasileiro, como um fenômeno semântico gradual de subjetificação.

No exemplo (8), observamos que o sujeito do verbo falar, explicitado pelo pronome ele, se caracteriza semanticamente como um agente que toma uma atitude e não apenas como um 
locutor em relação ao conteúdo proposicional que o verbo falar desencadeia e exprime na complementação.

(8) Aí ele falou pra menina conversar comigo. (MP, E149-BR-156)

Devem-se observar graus de subjetificação nos diversos contextos a serem analisados. Em um contexto em que se conceptualiza certo grau de generalidade do sujeito, o significado manipulativo da construção com o verbo falar fica mais dependente da contextualização e pode ser interpretado como mais atenuado, como se exemplifica em (9).

(9) É difícil você chegar na sua casa e falar para o seu pai não fazer uma coisa que ele faz há 50 anos. (MP, E173-BR-1426)

A interposição da expressão de dativo com a preposição para pode suscitar ambiguidade na interpretação de uma atitude mais ou menos manipulativa do sujeito. São casos de mesclagem, que consideramos de menor grau de manipulação, mas ressalvando que depende do contexto da construção. O exemplo (10), a seguir, favorece uma interpretação manipulativa, apesar de apresentar mesclagem.

(10) Chegamos em casa e ele me espancando, batendo, minha mãe foi perguntar, ele deu um tapa na cara dela, aí eu falei para ele não bater nela que quando eu crescesse eu ia matar ele. (MP, E214-BR-28)

Tomemos como exemplos algumas construções que comprovam um contexto favorável ao processo de mesclagem entre dativo com para e complemento com para infinitivo. A motivação cognitiva pode ser encontrada no fato de que tanto o dativo quanto o complemento do verbo pedir compartilham a conceptualização de alvo, algo a ser alcançado, finalidade.

(11) Alexandro, vou pedir para você para a gente começar, eu quero que você me diga o seu nome completo, o local e a data do nascimento. (MP, E123-BR-1) 
(12) Em 1994, eles resolvem abrir um escritório no Brasil, em Brasília e me pedem para eu e uma outra pessoa para vir abrir o escritório. (MP, E136-BR-1070)

A seguir, nos exemplos (13) e (14), deseja-se mostrar que uma possível variação entre uma construção formalmente mais complexa, com dativo e complementação com para infinitivo, e uma construção mais compacta, com mesclagem do dativo e sujeito do infinitivo, não se assenta apenas em uma diversidade formal, antes disso, essa variação reflete um contraste conceptual que se deixa explicar adequadamente em termos de operação de perspectiva.

(13) Ele me pediu pra assumir essa parte toda e eu continuei associado à Universidade nesse mesmo período. (MP, E151-BR-214)

(14) Aí o povo lá meu, pedia para eu ser presidente. (MP, E164-BR-79)

Os exemplos a seguir registram a construção FALAR PARA V. infinitivo em textos escritos, extraídos do corpus CONDIV-Port. Expressões explicativas, como em (15), e emprego do subjuntivo, em (16) e (17), colaboram para atenuar a manipulação.

(15) Por isso, falei para ele não desanimar, revelou. (CONDIV, BR-JSports-2000-49013)

(16) Se o Dino falar para eu ser ponta-esquerda, eu sou; se falar para ser centro- avante, estou lá. (CONDIV, BR-OEstadoSP-70-56037)

(17) Ainda houve quem me falasse para ingressar no Vitória de Setúbal, mas isso foi coisa que não passou de palavras... (CONDIV, PT-Bola-50-5695)

Finalmente, apresentamos a distribuição das construções PEDIR/FALAR PARA V. infinitivo, em PE e PB, na escrita (tabela 2) e na oralidade (tabela 3), segundo três subtipos de construções assim identificados:

Construção 1 (C1): PEDIR/FALAR PARA V. infinitivo, sem elementos intervenientes. 
Construção 2 (C2): PEDIR PARA dat./suj. V. infinitivo, com dativo interpretado como sujeito do infinitivo, exemplificando caso de mesclagem entre uma construção dativa e uma construção de complementação.

Construção 3 (C3): PEDIR PARA dat. PARA V. infinitivo, com duas preposições para que formalizam duas diferentes conceptualizações, a de dativo com para e a de complementação verbal com para infinitivo.

Os exemplos (18), (19) e (20), a seguir, apresentam esses três tipos de construção (C1, C2 e C3), respectivamente:

(18) Porque a professora, eu fugi da escola, pedi para sair e ela não deixou e eu fugi. (MP, E072-BR-1035)

(19) Eu até cheguei a ir em conventos pedir para as freiras rezarem. (MP, E072-BR-819)

(20) Vamos pedir para o Jânio Quadros para declarar aquelas florestas que nós vimos como Florestas Protetoras. (MP, E129-BR-593)

Tabela 2 - Construções PEDIR/FALAR PARA V. infinitivo na escrita

\begin{tabular}{ccccccc}
\hline & \multicolumn{2}{c}{ C1 } & \multicolumn{2}{c}{ C2 } & C3 \\
\cline { 2 - 7 } & PE & PB & PE & PB & PE & PB \\
\hline \multirow{2}{*}{ Pedir } & $7 / 7$ & $37 / 45$ & $0 / 8$ & $8 / 45$ & $0 / 7$ & $0 / 45$ \\
& $(100 \%)$ & $(83 \%)$ & $(0 \%)$ & $(17 \%)$ & $(0 \%)$ & $(0 \%)$ \\
\multirow{5}{*}{ Falar } & $2 / 2$ & $1 / 2$ & $0 / 2$ & $1 / 2$ & $0 / 2$ & $0 / 2$ \\
& $(100 \%)$ & $(50 \%)$ & $(0 \%)$ & $(50 \%)$ & $(0 \%)$ & $(0 \%)$ \\
\hline \multirow{2}{*}{ TOTAL } & $9 / 9$ & $38 / 47$ & $0 / 9$ & $9 / 47$ & $0 / 9$ & $0 / 47$ \\
& $(100 \%)$ & $(83 \%)$ & $(0 \%)$ & $(17 \%)$ & $(0 \%)$ & $(0 \%)$ \\
\hline
\end{tabular}

Tabela 3 - Construções PEDIR/FALAR PARA V. infinitivo na oralidade

\begin{tabular}{ccccccc}
\hline & \multicolumn{2}{c}{ C1 } & \multicolumn{2}{c}{ C2 } & \multicolumn{2}{c}{ C3 } \\
\cline { 2 - 7 } & PE & PB & PE & PB & PE & PB \\
\hline \multirow{2}{*}{ Pedir } & $13 / 13$ & $27 / 78$ & $0 / 13$ & $45 / 78$ & $0 / 13$ & $4 / 78$ \\
& $(100 \%)$ & $(36 \%)$ & $(0 \%)$ & $59 \%$ & $(0 \%)$ & $(5 \%)$ \\
\multirow{2}{*}{ Falar } & $1 / 2$ & $05 / 163$ & $1 / 2$ & $158 / 163$ & $0 / 2$ & $0 / 163$ \\
& $(50 \%)$ & $3 \%$ & $(50 \%)$ & $97 \%$ & $(0 \%)$ & $(0 \%)$ \\
\hline \multirow{2}{*}{ TOTAL } & $14 / 15$ & $32 / 241$ & $1 / 15$ & $203 / 241$ & $0 / 15$ & $4 / 241$ \\
& $(87 \%)$ & $(13,3 \%)$ & $(13 \%)$ & $(85 \%)$ & $(0 \%)$ & $(1,7 \%)$ \\
\hline
\end{tabular}


Observamos que os dados de escrita (Tabela 2) indicam o maior uso de PEDIR PARA infinitivo em PB, muito poucas ocorrências da construção FALAR PARA $V$ infinitivo na escrita em PB e em PE; essa construção ganha mesmo força na oralidade em PB, superando PEDIR PARA infinitivo. Entre os subtipos de construção, observe-se que C2 é a construção mais frequente na oralidade em PB. A construção C3 ocorre apenas na oralidade em PB, com o verbo pedir.

\section{Considerações finais}

O exame das construções com os verbos PEDIR/ FALAR PARA infinitivo sob a ótica da Linguística Cognitiva demonstra, a nosso ver, o princípio de que a semântica é primariamente cognitiva, pois é o "entendimento em conjunto", ou seja, uma dada conceptualização sob uma dada perspectiva que constitui gradualmente os processos de mudança na língua e, também, os processos de estabilização. Há muitos conceitos ainda por serem trabalhados, mas, por ora, pensamos que há principalmente necessidade de um número maior de trabalhos que examinem a diversidade de construções, pois, quanto mais questões linguísticas possam ser esclarecidas ao fazer uso de noções como a de perspectiva e subjetividade, mais bem validados se tornarão os princípios teóricos. Trata-se, pois, de um desafio e também de um grande incentivo aos que se dedicam ao exame das construções linguísticas em uso, considerando evidentemente os sujeitos que se fazem atuantes em operações específicas de perspectivação.

\section{REFERÊNCIAS}

COSTA, L. Resumo da actividade da Linguateca de 16 de dezembro de 2006 a 31 de dezembro de 2007. Disponível em: < https://www. linguateca.pt/documentos/RelatorioLinguateca2007.pdf $>$. Acessado em 11 jun. 2018.

GEERAERTS, D.; CUYCKENS, H. (eds.). Cognitive Linguistics. New York: Oxford University Press, 2007.

FAUCONNIER, G.; TURNER, M. The way we think: conceptual blending and the mind's hidden complexities. New York: Basic Books, 2002. 
LANGACKER, R. W. Foundations of Cognitive Grammar. Vol. I: Theoretical Prerequisites. Stanford: Stanford University Press, 1987.

. Cognitive Linguistics. In: GEERAERTS, D.; CUYCKENS, H. (eds.). Cognitive Linguistics. New York: Oxford University Press, 2007.

. Cognitive grammar: a basic introduction. New York: Oxford University Press, 2008.

MENEZES, V. M. C. de. Construções infinitivas iniciadas por para: oracionalidade e redução. Tese de doutorado. Rio de Janeiro: UFRJ/FL, 2001.

. Referenciação e letramento: o uso de expressões préfabricadas. Matraga, Rio de Janeiro, UERJ, Instituto de Letras, v. 22, n. 36, p.145-160, 2015.

Construções "ter SN para infinitivo" sob a ótica da Gramática Cognitiva. Revista Portuguesa de Humanidades Estudos Linguísticos. Vol. 1, fasc. 1, 2017.

MONDADA, L.; DUBOIS, D. Construção dos objetos do discurso e categorização: Uma abordagem dos processos de referenciação. In: CAVALCANTE, M.; RODRIGUES, B. B.; CIULLA, A. (org.). Referenciação. Clássicos da Linguística, vol. 1. São Paulo: Contexto, 2003, p. 17-52.

SILVA, A. S. da. (Inter) subjetificação na linguagem e na mente. Revista Portuguesa de Humanidades - Estudos Linguísticos, 15-1, p. 93-110, 2011.

. Perspectivação conceptual e gramática. Revista Portuguesa de Humanidades - Estudos Linguísticos, 12-1, p. 17-44, 2008.

SILVA, A. S. da.; BARTORÉO, H. J. Gramática Cognitiva: estruturação conceptual, arquitectura e aplicações. In: BRITO, A. M. (org.). Gramática: História, Teorias, Aplicações. Porto: Fundação Universidade do Porto, 2010, p. 229-251. 
TALMY, L. Toward a Cognitive Semantics. Vol. II: Typology and process in concept structuring. Cambridge, Mass.: The MIT Press, 2000.

TORRENT, T. T. A Rede de Construções em Para (SN) infinitivo: Uma abordagem centrada no uso para as relações de herança e mudança construcionais. Tese de Doutorado. Rio de Janeiro: UFRJ/FL, 2009.

TRAUGOTT, E. C. On the rise of epistemic meanings in English: an example of subjetification in semantic change. Language 65, p. 31-55, 1989.

TRAUGOTT, E. C.; DASHER, R. B. Regularity in Semantic Change. Cambridge: Cambridge University Press, 2002.

TRAUGOTT, E. C.; TROUSDALE, G. Constructionalization and constructional changes. New York: Oxford University Press, 2013.

VANDERSCHUEREN, C. Infinitivo y sujeto en portugués y español. Un estudio empírico de los infinitivos adverbiales con sujeto explícito. Berlin/Boston: De Gruyter, 2013.

VERHAGEN, A. Construal and Perspectivization. In: GEERAERTS, D.; CUYCKENS, H. (eds.). Cognitive Linguistics. New York: Oxford University Press, 2007. p.48-81. 


\section{Abstract \\ When speaking becomes demanding: the construction FALAR PARA V. infinitive in Portuguese, a cognitive explanation}

In this paper, we focus on the construction FALAR PARA V.infinitive in Brazilian Portuguese $(B P)$, in oral and written modalities, in contexts in which a manipulative sense emerges. The sharing of semanticgrammatical domains between the verbs pedir (to ask) and falar (to speak), such as the conceptualization of communicative activity through the use of the word and the possibility of finite and nonfinite complements, directed us to an investigation on the similarities and differences the constructions with these verbs exhibit. Based on this, we contrasted with European Portuguese (EP), in the same synchrony, taking into account the cognitive belief that semantic diversities are the result of different conceptualizations. Therefore, we try to identify the cognitive operations involved in the conceptualization processes profiled by the speaker's choice, considering both conventionality and semantic change. The concepts of perspectivization and subjetification, taken from Traugott's (1989), Traugott and Dasher's (2002) and Langacker's (2008) studies, oriented our data analysis, which highlights the construction FALAR PARA V.infinitive as an instance of the process of semantic change in Brazilian Portuguese (BP), in both oral and written modalities.

Keywords: Construction FALAR PARA $V$. infinitive. Subjetification. Cognitive Linguistics 